\title{
Pergunta de criança: oportunidades formativas para professores em serviço a partir dos questionamentos sobre fenômenos da natureza por crianças do primeiro ciclo da alfabetização
}

Children's question: formative opportunities for teachers in service from questions about nature phenomena by children in the first cycle of literacy

Geníria Almeida dos Santos Souza ${ }^{l}$ Adriane Lizbehd Halmann ${ }^{2}$

\begin{abstract}
RESUMO
O potencial para oportunidades formativas a partir de questionamentos das crianças do ciclo da alfabetização sobre os fenômenos da natureza foi o principal objeto deste estudo, realizado em uma Escola Municipal de Ensino Fundamental dos anos iniciais, no município de São José da Vitória-Bahia. Para tanto, foi realizada uma pesquisa qualitativa do tipo pesquisa participante, visto que foca no caráter subjetivo o comportamento dos professores e o objeto proposto. A pesquisa foi desenvolvida a partir da realização de uma entrevista semiestruturada gravada em áudio e depois transcrita; uma oficina e uma entrevista final com os docentes para analisar as perspectivas de mudança na prática pedagógica, no que diz respeito ao questionamento dos alunos. Os dados demonstram que ainda é presente uma abordagem conteudista, na concepção de que o docente deve responder as perguntas dos discentes e trazê-los de volta para a aula. Entretanto, após vivenciar a possibilidade do questionamento como estruturante do planejamento, os docentes afirmaram a possibilidade de construir novas aprendizagens mais significativas, além de considerarem esta uma oportunidade importante de formação docente continuada em serviço.
\end{abstract}

Palavras-chave: Questionamento reconstrutivo; Prática docente; Formação continuada de professores; Educação em Ciências.

\begin{abstract}
The potential for formative opportunities from the literacy cycle children's questions about the nature phenomena was the main object of this study, developed in a municipal elementary school of the early years, in São José da Vitória, Bahia. For that purpose, a qualitative research of the participant research type was performed, since it focuses on the subjective character the teachers behavior and the proposed object. The research was developed from a semi-structured interview recorded in audio and later transcribed; a workshop and a final interview with the teachers to analyze the perspectives of change in the pedagogical practice, regarding the students questioning. The results demonstrate that a content approach is still present, in the conception that the teacher should answer the students' questions and bring them back to class. However, after experiencing the possibility of questioning as a structuring of planning, the teachers affirmed the possibility of building more meaningful new learning, in addition to considering this an important opportunity for continuing in-service teacher training.
\end{abstract}

Keywords: Reconstructive questioning; Teaching practice; Continuing teacher training; Science Education.

\footnotetext{
${ }^{1}$ Docente das redes municipais de ensino de Itabuna e São José da Vitória (BA). Pedagoga e Mestre em Educação pela Universidade Estadual de Santa Cruz. janasouza10@yahoo.com

2 Professora adjunta da Universidade Estadual de Santa Cruz, Licenciada em Ciências Biológicas (UFSM), Mestre e Doutora em Educação (UFBA). adriane_halmann@yahoo.com.br
} 


\section{Primeiros questionamentos e embasamentos}

O primeiro ciclo da alfabetização é uma etapa em que os educandos estão numa fase de grande exploração do seu entorno, questionando-o mesmo se não forem instigados para isso. Nessa faixa etária, o aluno pergunta sobre qualquer fenômeno que venha acontecer em seu meio, seja por curiosidade ou interesse de compreender o que ainda desconhece. Os questionamentos das crianças são bastante comuns nos anos iniciais e se constituem como atributos importantes no processo de construção de novos conhecimentos.

De acordo com Demo (2015), a aprendizagem perpassa por diversos fatores, um deles é o conhecimento prévio adquirido das observações e das relações com seus pares. O referido autor afirma que, nessa fase da criança, a presença de mediadores é importante para auxiliar na reconstrução do que já é conhecido, conduzindo-os a novas descobertas. Para Moraes (2003), as perguntas têm significado mais efetivo quando são conectadas ao conhecimento prévio dos alunos, ou seja, os saberes que os alunos já trazem e que podem agir como ponte para emergir outras aprendizagens.

Tratar o conhecimento na perspectiva de uma pedagogia libertadora defendida por Freire (1996) torna a aprendizagem mais interessante e viável, sobretudo por ter sido gerada do horizonte contextual do sujeito aprendiz. Esse caminho leva a um saber construído e reconstruído advindo da capacidade produtiva do individual para o coletivo. No processo de aprendizagem, os alunos passam da condição de ouvintes para atuantes no seu processo de construção de conhecimento, pois realizam uma complementação no diálogo com outros, confrontando ideias, reconstruindo saberes advindo de uma construção coletiva. Freire e Faudez (1995) argumentam que questionar é criar condições de avançar, esse é um momento propício para colocar em movimento os saberes que precisam ser organizados, explicitados por meio da problematização.

Considerando os saberes trazidos das vivências dos educandos, o professor tem a responsabilidade de problematizar situações de forma a possibilitar o progresso da aprendizagem e explicitação do conhecimento nos diversos campos das linguagens. $\mathrm{O}$ questionamento do aluno, associado com as intervenções do professor, pode ser o ponto crucial para a construção e reconstrução de saberes, direcionando-os para uma pesquisa cada vez mais sofisticada. Outro fator importante está centrado no contexto da reflexão da prática docente numa dimensão metodológica pautada no saber, como oportunidade de pensar sobre o seu ensino e rever a possibilidade de (re)planejamento.

$\mathrm{O}$ educador age propondo desafios específicos ao colocar o educando em condição ativa de construção de conhecimento, a instigar o que sabe a partir dos conceitos construídos ao longo da vida, emergindo novos saberes e interligando o pensamento e a ação no percurso de evolução cognitiva. Para Delizoicov e Angotti (1994, 
p.56), o exercício da cidadania requer "um mínimo de formação básica em Ciências [...] de modo a fornecer instrumentos que possibilitem uma melhor compreensão da sociedade".

A formação dos professores, nesse contexto, possibilita desenvolver o processo instigador e questionador para o exercício da cidadania, a tornar o ambiente educativo aberto, no intuito de construir um espaço provocador de situações que despertem, nos educandos, a curiosidade e o interesse pela (re)construção de suas ideias.

Entendendo que a ação educativa deve estar articulada com a vida real dos alunos, nos propomos a investigar como os professores reagiam frente aos questionamentos sobre os fenômenos da natureza por parte dos alunos. Buscamos saber se os questionamentos dos alunos repercutiam de alguma forma nos planejamentos docentes, se alteravam suas práticas e se eram mote para a formação contínua em serviço destes docentes. Diante do exposto, nos questionamos: Como acontecem as práticas dos professores do primeiro ciclo de Alfabetização frente aos questionamentos dos alunos sobre os fenômenos da natureza? Esse problema conduziu a uma pesquisa de mestrado em Educação, cujo objetivo geral foi compreender as práticas dos professores do primeiro ciclo de alfabetização frente aos questionamentos dos alunos sobre os fenômenos da natureza, em uma escola municipal de ensino Fundamental, nos anos iniciais, no município de São José da Vitória, Bahia. Para este artigo, traremos um recorte dos dados que nos permitam as práticas e as oportunidades formativas frente aos questionamentos dos alunos sobre os fenômenos na natureza.

\section{O percurso, os olhares e as ações}

Para alcançar os objetivos propostos, foi traçada uma pesquisa qualitativa, com o contato direto do pesquisador com o ambiente e situação investigada (LÜDKE; ANDRÉ, 2014). Foi traçada uma abordagem participante, entendida como a pesquisa epistemológica na qual pesquisador e pesquisados são sujeitos ativos da produção do conhecimento, numa relação dialógica entre o pesquisado e o pesquisador (LÜDKE; ANDRÉ, 2014).

A pesquisa foi realizada na Escola Municipal Guilhermina Cabral, localizada em São José da Vitória, um município do interior da Bahia, com aproximadamente $6 \mathrm{mil}$ habitantes, predominantemente zona rural e repleto de áreas remanescentes de mata atlântica. A escola é de pequeno porte, com sete salas de aula, 12 docentes (com graduação) e 3 auxiliares (com Magistério/Ensino Médio), onde é possível encontrar classes dos anos iniciais do ensino fundamental. No ano de 2018, a escola atendeu 225 alunos entre 06 a 08 anos, nos turnos matutino e vespertino. Esse contexto no qual se insere a escola se mostrou especialmente promissor para a realização da pesquisa, uma vez que as crianças experienciam o contato com a natureza e trazem para a escola várias inquietações sobre os seus fenômenos, ao mesmo tempo que os professores possuem formações iniciais que pouco contemplaram as ciências, mas que 
estão inseridos em uma gestão que incentiva a formação em serviço.

A pesquisa foi realizada após aprovação do projeto pelo Comitê de Ética em Pesquisa da Universidade Estadual de Santa Cruz (Protocolo 77608217.9.0000.5526, aprovado pelo Parecer 2.336.504, de 18 de outubro de 2017). A pesquisa foi organizada em três etapas distintas. Na primeira etapa, foram realizadas entrevistas com os docentes para compreender suas oportunidades formativas e algumas concepções das práticas em relação aos questionamentos dos alunos. A segunda etapa foi um conjunto de oficinas com os professores, construídas a partir de cenas cotidianas, inspiradas nas falas dos professores durante as entrevistas, de forma que os docentes vivenciassem conjuntamente situações com os questionamentos dos alunos, refletissem e construíssem colaborativamente práticas mais favoráveis. Por fim, a terceira etapa foi uma nova entrevista com os docentes, buscando identificar repercussões das oficinas nas estratégias pedagógicas cotidianas dos professores.

\section{Entrevistas}

Na primeira etapa, foi realizada uma entrevista semiestruturada, individual, gravada em áudio, agendadas em momentos apropriados a cada um dos professores. Na entrevista inicial, foram realizadas dez perguntas que permitiram compreender aspectos realizados a compreensão das oportunidades formativas das professoras, e aspectos relacionados aos questionamentos que os estudantes fazem para as professoras, como a relevância que as professoras atribuem a esses questionamentos para o processo de aprendizagem e como esses questionamentos são (ou não são) aproveitados em sala de aula, o que nos permitiu compreender as posturas das professoras frente aos questionamentos dos educandos. Após a oficina, foi realizada uma nova entrevista, aos mesmos moldes da primeira, mas, dessa vez, com questões voltadas para compreender repercussões das oficinas no fazer pedagógico cotidiano dos docentes.

\section{Oficina}

As oficinas objetivaram identificar as vivências dos professores em relação aos questionamentos dos alunos, suas relações com os saberes e com a construção do conhecimento, dando ênfase na possibilidade de diálogos com os professores para o desenvolvimento de uma prática argumentativa sobre as finalidades dos questionamentos dos alunos, como tentativa de reflexão do fazer pedagógico.

Durante as entrevistas, as professoras foram questionadas sobre situações em que os alunos trouxeram questionamentos sobre os fenômenos da natureza, seguido de questionamentos sobre como isso repercutiu nas práticas dos docentes. Esses relatos serviram de inspiração para a criação de "cenas cotidianas", com personagens fictícios.

Organizamos um momento de discussão com o coletivo da instituição, para construir conhecimento a partir da ação e da reflexão da experi- 
ência dos educadores e discussões de textos acerca da temática abordada. A princípio seria apenas uma oficina de três horas, mas, frente a aceitação dos docentes e solicitação da gestão da escola, nosso trabalho foi inserido no calendário de formação da mesma escola, constituindo, assim, um momento de formação continuada em serviço.

A partir dos questionamentos relatados pelas docentes montamos um paralelo com alguns teóricos que defendem os questionamentos dos alunos como elemento importante para a construção do conhecimento e reflexão da prática pedagógica. Este material foi levado na forma de slides e discutido com as professoras. Logo após, realizamos reflexões acerca das práticas, pautado nos conceitos de professor reflexivo como agente instigador da prática, dos saberes dos alunos, que problematiza situações cotidianas relacionadas aos conhecimentos existentes dos alunos, através do diálogo, da leitura, da reflexão e das interações (PIMENTA, 2006).

Segundo Freire (1996, p.86), ensinar exige disponibilidade para o diálogo, pois "o sujeito que se abre ao mundo e aos outros inaugura com seu gesto a relação dialógica em que se confirma como inquietação e curiosidade, como inconcluso em permanente movimento na História”. Após as discussões, as professoras retomaram com as perguntas e sistematização para discutir uma proposta de procedimentos didáticos que atendessem aos questionamentos dos alunos.

\section{Análise dos dados}

Após a coleta dos dados, todos foram transcritos e tratados. $\mathrm{O}$ nome dos participantes foi suprimido e substituído pelo nome de flores da flora brasileira, garantindo, assim, o anonimato e o sigilo, preservando a identidade de cada docente. Procuramos desenvolver uma análise que ajudasse a compreender o problema investigado de maneira a interpretá-lo com mais consistência, assim procedendo a Análise Textual Discursiva (ATD), que consiste em "um processo que se inicia com uma unitarização em que os textos são separados em unidades de significado. Estas unidades por si mesmas podem gerar outros conjuntos de unidades oriundas da interlocução empírica, da interlocução teórica e das interpretações feitas pelo pesquisador" (MORAES; GALIAZZI, 2006, p. 118).

Assim, foi feita uma leitura atenta e minuciosa, em paralelo com uma escuta densa, retomando sempre o objeto de estudo para assimilar trechos que contemplassem os objetivos da pesquisa e atendessem também o problema de pesquisa. Tentou-se captar significados comuns dos discursos, agrupando respostas por semelhanças de conteúdos, que foram agrupados em categorias, o que nos permitiu construir uma nova leitura e compreensão sobre o objeto da pesquisa. Desse movimento, emergiram as categorias de análise, conforme explicitado no quadro abaixo (Quadro 1):

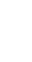


Quadro 01: categorias de análise da pesquisa

\begin{tabular}{|l|l|}
\hline CATEGORIAS & SUBCATEGORIAS \\
\hline $\begin{array}{l}\text { 1- Oportunidades formativas dos } \\
\text { professores e organização do traba- } \\
\text { lho pedagógico. }\end{array}$ & $\begin{array}{l}\text { 1A - Importância da formação continuada. } \\
\text { 1B - Trabalho pedagógico }\end{array}$ \\
\hline $\begin{array}{l}\text { 2- Práticas e vivências dos professo- } \\
\text { res em relação aos questionamentos } \\
\text { dos alunos. }\end{array}$ & $\begin{array}{l}\text { 2 A - Questionamentos articulados com a prática. } \\
\text { 2 B - Importância dos questionamentos dos alunos. } \\
\text { 2 C - Como organiza prática a partir dos questionamentos dos } \\
\text { alunos. }\end{array}$ \\
\hline
\end{tabular}

FONTE: Dados da pesquisa

A análise do conjunto dos dados permitiu compreender as práticas dos docentes do primeiro ciclo de alfabetização frente aos questionamentos dos alunos sobre os fenômenos da natureza. A pesquisa possuía um conjunto de objetivos específicos, mas, destes, optamos por aqui centrar as análises em relação às práticas e às oportunidades formativas frente aos questionamentos dos alunos sobre os fenômenos da natureza. Sendo assim, traremos dados e análises especificamente sobre parte das categorias 1 e 2 , sendo que o conjunto completo de dados e análises pode ser encontrada na dissertação na íntegra.

De questionamentos, reflexões, formações e reformulações: o processo da formação de professores em serviço a partir dos porquês dos discentes

Aqui serão tecidas análises de falas coletadas nos distintos momentos da pesquisa, seja na entrevista inicial, nas oficinas ou na entrevista final, sendo que os dados foram organizados de acordo com as categorias de análise construídas. A primeira etapa da coleta de dados se deu por meio de uma en- trevista inicial semiestruturada com os professores. Os primeiros aspectos questionados nos permitiram traçar um perfil dos docentes, que, para preservar sua identidade, serão aqui tratados pelo codinome de flores da flora brasileira. Concordaram em participar da pesquisa 12 docentes, todas do sexo feminino, duas possuíam formação em nível médio, com o curso de Magistério, sem formação em nível superior, atuando como auxiliares. Das demais, todas possuíam formação em nível superior, Licenciatura, sendo 4 em Pedagogia, 3 em Letras, 1 em Biologia, 1 em Geografia e 1 em História. No momento da entrevista, duas lecionavam no primeiro ano, quatro no segundo ano e seis no terceiro ano do ciclo de alfabetização.

Para compreender as oportunidades formativas dos professores e as concepções pedagógicas que subsidiam suas práticas frente aos questionamentos dos alunos sobre os fenômenos da natureza, foi perguntado aos participantes da pesquisa: Qual a importância da formação continuada? Destacamos algumas das respostas:

Todas as formações foram e são importantes para ampliar os meus conhecimentos, né. (Professora Rosa). 
Olha só... A formação continuada, sem ela eu não teria continuado é..., a minha profissão que é professora porque eu fiz a formação e encontrei profissionais assim muitos parceiros que me ensinaram muito. Colegas professores de sala de aula, eu digo que na formação eu aprendi mais com as colegas, quando compartilham as dúvidas, as angustias, as experiências das suas aulas, então eu vi que sem a formação continuada eu não estava na sala de aula... Alfabetizadora de qualidade é a partir das formações (Professora Margarida).

O bom da formação é que adquirimos conhecimentos novos, para saber como lidar com os alunos em forma de disciplina através de uma nova rotina pedagógica que temos na escola (Professora Hortência).

As falas das docentes demonstram que atribuem grande importância à formação continuada, no sentido de ampliar os conhecimentos e transpor para prática em forma de disciplina. Também como forma de lidar com os alunos, ressignificando a prática pedagógica. A postura de cada professor ilustra muito claramente que a formação continuada é necessária, mas que as interações materializam os saberes a partir das reflexões e das experiências expressadas nos encontros formativos.

Percebe-se que há o entendimento que a formação continuada permite desenvolver um trabalho com os alunos. Sendo assim, é notório que a formação em uma das falas acontece de fato a partir das discussões nos encontros com os colegas valorizando a construção de saberes. Freire (2006) argumenta que:
Será privilegiada a formação que se faz no âmbito da própria escola, com pequenos grupos de educadores ou com grupos ampliados, resultantes do agrupamento das escolas próximas. Este trabalho consiste no acompanhamento da ação - reflexão - ação dos educadores que atuam nas escolas; envolve a explicação e análise da prática que requerem considerando a reflexão sobre a prática e a reflexão teórica. (FREIRE, 2006, p.81)

Não há dúvida que o espaço da escola pode se constituir em um ambiente integrado, que pode e deve promover meios que facilitem discussões entre os indivíduos com suas singularidades culturais, seus diversos fazeres pedagógicos. Ouvir o outro consiste em um refazer e fazer a prática mediante uma ação-reflexão-ação.

Os encontros formativos fazem parte do processo de construção de conhecimentos e construção da identidade profissional, pois, nesses encontros, são geradas discussões da prática que, de forma bastante crucial, fortalece suas ações pedagógicas, concretizando um fazer pedagógico mais reflexivo, a (re)construção da prática; embora demonstre que as interações das colegas possam mediar uma construção acerca de um planejamento mais eficaz, possibilitando, assim, momentos para sanar as dificuldades.

Muito se tem discutido sobre a formação continuada nos últimos anos, mas é importante ter um olhar sobre a trajetória desse contexto nos aspectos que fundamentaram ao longo do tempo as atividades na prática do docente. De acordo com Nóvoa (1992) e Schön (1997), a formação continuada é fun- 
damental para o exercício da docência. Ela também é contemplada pela Lei de Diretrizes e Bases, que, em seu artigo 67, inciso $\mathrm{V}$, determina em caráter obrigatório a formação continuada (BRASIL, 1996).

Para compreender se as inquietações dos estudantes eram consideradas como promotoras do trabalho pedagógico, ou se os questionamentos das crianças repercutiam de alguma forma no planejamento docente, questionamos como as docentes organizavam o seu trabalho pedagógico. Constatamos nas narrativas da maioria das entrevistadas que elas organizam seu trabalho pedagógico a partir dos encontros de planejamento pedagógico com a coordenação da escola, a saber, a escola utiliza a pedagogia de projeto, relatado a seguir por alguns participantes da pesquisa. Destacamos aqui algumas falas das docentes:

Eu organizo a partir dos projetos é, e também socializando as ideias com as colegas como eu falei né. As dificuldades, que temos procuramos é... Através de gêneros textuais, através de autores da educação a gente está organizando. (Professora Tulipa).

Eu, no meu caso, organizo assim: existe o planejamento semanal organizado pela gestora e coordenadora, a partir daí desenvolvo minhas atividades com conteúdos a partir daí dentro desse texto, trabalho a letra inicial e a final, palavras, frases, é tudo contextualizado de acordo o texto e o tema do projeto. (Professora Margarida).

Analisando essas respostas, fica claro que a organização do trabalho pedagógico é feita a partir do direcio- namento do corpo diretivo nos encontros pedagógicos semanais, a partir daí programam os conteúdos necessários para explicitar aos alunos. Embora se discuta muito sobre uma proposta que evidencie os conhecimentos prévios dos alunos, na maioria, vemos professores que utilizam de documentos prescritivos dependendo de uma orientação didática do corpo diretivo, como mostra claramente as narrativas apresentadas. Há evidência de uma prática que não apenas transmite o conteúdo, mas despreza o fator mais importante que são os conhecimentos que os alunos trazem.

A transmissão do conhecimento se caracteriza no contexto da educação bancária tão criticada por Freire (1996, p.27), que afirma que "ensinar não é transferir conhecimento, mas criar possibilidades para sua própria produção ou a sua construção". Conforme o autor, é necessária uma prática que valorize os conhecimentos do sujeito, que o estimule, invista na capacidade de sua interação com os outros, reestruturando seus esquemas de conhecimentos e o constituindo num sujeito ativo e participativo.

Tendo compreendido o perfil dos docentes, as suas compreensões sobre a formação continuada e suas relações com o trabalho pedagógico, como produto derivado da açãoreflexão-ação, passamos a investigar como os questionamentos dos alunos influenciam nas práticas e vivências dos professores. Inicialmente buscamos compreender as formas como os questionamentos dos estudantes se articulam à prática docente. As falas das docentes impulsionaram análises sobre 
as práticas adotadas pelas professoras frente aos questionamentos que os alunos fazem e como estas professoras articulam sua prática. Perguntamos: Como você articula os questionamentos dos alunos com a sua prática pedagógica? Destacamos aqui as seguintes falas:

Eu busco responder em uma linguagem simples com exemplo do cotidiano dos meus alunos e acrescentando sinalizações dos meus alunos no meu planejamento (Professora Tulipa).

Eu faço através de aulas preparadas, com vocabulário de fácil entendimento para eles (Professora Begônia).

Tenho que procurar conscientizar meu aluno de acordo com a área que estou trabalhando, fazendo um paralelo com esse trabalho (Professora Jasmim).

As narrativas apresentadas mostram que, por vezes, os questionamentos dos alunos não repercutem diretamente no replanejamento das ações pedagógicas em função da aprendizagem. As professoras procuraram responder as perguntas trazidas por eles ou tentaram chamar os alunos para o tema da aula que estavam ministrando no momento, todavia, não demonstraram reconhecer e integrar os conhecimentos trazidos por eles, os colocando em condição passiva, como meros ouvintes.

A prática docente, nessa perspectiva, não contribui para a formação de um sujeito autônomo, pois não valoriza os conhecimentos prévios e a curiosidade crítica, condição que é inerente ao ciclo da alfabetização, modalidade ministrada pelas professoras.
Foi solicitado às participantes da pesquisa que citassem exemplo de alguns questionamentos trazidos pelos alunos e qual a prática e atitude tomada frente a tais, as professoras responderam:

As questões folclóricas são muito fortes, né? A gente mora em uma comunidade que tem rios, então eles perguntam muito em relação ao folclore, se realmente existe. Uma das perguntas mesmo da minha aluna foi: mula sem cabeça existe? Ai nós fomos para o dicionário, né. Pedi para que ela procurasse no dicionário significado de lenda, o significado de mito e a partir desses significados nós fomos pra conversa oral (Professora Tulipa).

Alguns me questionam mais na época do folclore, sobre curupira, saci-Pererê, essas coisas, aí vem os mitos, as lendas, aí eu fui explicar de acordo, peguei um dicionário fui dizer o que é lenda, o que é mito e tal. Ó tia não sabe, a tia vai pesquisar, tia vai procurar saber, às vezes a tia esquece (RISOS) e fica em débito né. Mas aí, como eles são crianças, assim, aí vou com jogo de cintura depois digo que pesquiso, ou então você mesmo pesquise e fale e passa para sua tia, sua tia trabalha tanto... Acabo resolvendo a situação (Professora Rosa).

Na primeira narrativa, a professora Tulipa demonstra um cuidado de envolver o aluno utilizando o dicionário para um conhecimento conceitual e, em seguida, provoca uma atividade a partir da oralidade. Entretanto, a professora Rosa ouve o aluno e deixa claro desconhecer o conteúdo que em outro momento poderá responder sem preocupação com os saberes trazidos do seu entorno. 
A seguir, buscamos compreender a importância dos questionamentos dos alunos e como as professoras trabalham com eles em suas práticas, no sentido de compreendê-los em suas vivências para construção dos saberes. Foi realizada a seguinte pergunta: Os questionamentos sobre os fenômenos da natureza trazidos pelos alunos são importantes e podem ser inseridos na organização do seu planejamento?

Sim, são de extrema importância. E sempre eu insiro nos planos de aula os questionamentos feitos por eles. $\mathrm{Eu}$ sempre os coloco... perguntamme hoje, aí se não tiver uma resposta cabível pra dar para ele eu em casa pesquiso, coloco no próximo plano pra poder satisfazer a turma e a todos (Professora Cravo).

Com certeza, são inseridos sim... a partir dos questionamentos trazidos por cada aluno, eu procuro desenvolver minhas aulas e procuro também elaborar minhas atividades baseadas no conhecimento de cada aluno. Assim procede a minha aula (Professora Jasmim).

Analisando essas duas respostas, fica explícito que os questionamentos dos alunos são importantes, mas são inseridos na prática pedagógica como um conteúdo à parte. Nessa perspectiva, não colocam o aluno no confronto com os saberes do cotidiano, sem o envolver nesse processo de busca de integração do conhecimento com o vivido, embora o momento seja para construção dos conhecimentos e superação das lacunas conceituais.

Pode-se notar que, na perspectiva apresentada, o questionamento do aluno precisa da resposta do professor. Mas os questionamentos são possibili- dades de avançar na aprendizagem, como também um caminho para a reflexão da prática. Sobre isso, vejamos outras falas:

\begin{abstract}
Os alunos já vêm para a sala de aula trazendo uma bagagem, é nós temos que aproveitar o conhecimento prévio, a fim de melhoria de seu próprio conhecimento (Professora Begônia).

Pode sim e principalmente nós podemos "casar" esse é... essa questão em relação a assuntos sobre a nossa cidade, ao aluno como ser participante na sociedade, porque ele se percebe atuante, ele é parte né daquele meio. Então quando a gente insere esses questionamentos toda essa proposta a realidade da criança ele não se sente indiferente, aquilo que ele está vivendo, ele sente parte de algo e que ele tem responsabilidade para tal (Professora Orquídea).
\end{abstract}

Nessas falas, é possível perceber que o conhecimento trazido e discutido é uma forma do aluno se sentir pertencente e participante na sociedade em que vive. Para compreendermos melhor esse aluno, é necessário criar situações que ele possa construir sua autonomia por meio do questionamento. O aluno precisa compreender sua posição como alguém capaz de crescer, de construir e produzir algo novo. $\mathrm{O}$ alicerce dessa postura é o questionamento, já que faz que o aluno elabore ao invés de copiar (MORAES; RAMOS; GALIAZZI, 2004). Nessa perspectiva, o professor precisa organizar uma prática que possibilite ferramentas para que o aluno, por meio dos questionamentos, possa criar mecanismos de aprendizagem. Foi perguntado ao professor que tipo de atividade propõe considerando o que os 
alunos trazem dos conhecimentos (questionamentos) e, assim, emergindo a seguinte subcategoria.

Algumas falas nos permitiram analisar se os questionamentos dos discentes contribuem para a construção ou reconstrução dos planejamentos e das práticas dos docentes:

O aluno conta um fato ocorrido, geralmente tem crianças que... Nós temos trabalhado com crianças nós sabemos o quanto elas são curiosas, então ele, traz um fato de casa, porque a gente que está frente a frente com a classe de criança, a gente sabe que ela traz uma imensa bagagem de casa e essa bagagem que o aluno traz nós devemos estar sempre aproveitando. Assim, um aluno traz um fato que ocorreu, ele conta aquele fato, eu deixo contar da forma dele, procuro ouvir com muita atenção e procuro propor uma atitude, uma atividade de forma que ele relate construindo assim um texto descritivo e fazendo uma apresentação em sala. E aí vou pedir depois que explique leia perante os colegas de classe, explique aquele texto que ele mesmo construiu, pensa que estou levando meu aluno a construir e apresentar perante os outros alunos e perante a classe (Professora Jasmim).

Diante do que ele me trouxer no meu caso faço a explicação oral e se não for naquele momento que não tiver, não puder fazer, mas depois eu trago algo para dá um suporte pode fazer uma criação de texto, dentro daquilo que eles criaram, posso trazer uma história, mas no outro dia, entendeu? Uma palavrinha cruzada, alguma coisa desse jeito diferente pra fortalecer tudo isso (Professora Hortência).

As narrativas esclarecem que as professoras montam estratégias, ati- vidades de trabalho baseado no que os alunos trazem, mas acontece uma ausência de interagir o aluno no processo de construção dos conhecimentos, resumindo a meras atividades, sem a preocupação de problematizar o conhecimento trazido por eles: "É preciso saber que ensinar não é transferir conhecimentos, mas criar as possibilidades para sua própria produção ou construção" (FREIRE, 1996, p.25).

Essa posição de Freire (1996) permite-nos repensar a prática no âmbito da sala de aula em seus múltiplos fatores, dentre eles, a condição que damos aos alunos a partir da valorização dos seus saberes confrontarem conhecimentos, selecionar e aprender com os elementos disponíveis do seu entorno.

A prática docente é considerada um lócus de formação e produção de saberes, segundo Veiga e D'Ávila (2012). Há de se considerar que as experiências vividas na oficina e a produção sistematizada vão se entrelaçando dando outros significados a conceitos enraizados a partir das reflexões da prática, produzindo inovação dos saberes e, consequentemente, inovação das práticas.

A partir da oficina, foi perceptível que as professoras demonstraram uma conduta perceptiva por meio dos questionamentos dos alunos, como um momento de refazer o plano, de ressignificar a prática, resultando em uma estrutura organizativa pedagógica. Percebemos que ficou o desejo de mudança em algumas professoras, na certeza de aprimorar os conhecimentos refletindo a prática através das experiências vivenciadas relativo ao plane- 
jamento e aos questionamentos que os alunos trazem para a sala de aula do seu entorno. Em se tratando de mudança como condição de melhorar a prática, a reflexão da ação contribui para o processo de formação constante, pois, a partir dessa reflexão da prática, o professor aprimora seu desenvolvimento profissional (VEIGA; D’ÁVILA, 2012, p. 40), reconstruindo e reformulando conceitos. Algumas falas ilustram isto:

Entendi que os questionamentos trazidos por eles podem transformar todo o nosso planejamento, fazendo com que possamos está sempre em busca de algo novo. (Professora Cravo).

Passei entender que é muito importante para os discentes se expressarem. (Professora Tulipa).

Sobre os questionamentos dos alunos, que é inevitável, não é correto diante de um questionamento da criança passar despercebido, pois a partir do momento que uma criança ela faz uma pergunta, ele já tem um conhecimento, ela já está envolvida em um contexto, então a partir do momento que ela faz aquela pergunta você percebe que ela está no contexto da aula e que você percebe que ela está numa fase que você espera no nível que ela esteja. Percebi também que os conhecimentos prévios, é você pegar os conhecimentos prévios do aluno, pois é tudo e faz a diferença na aprendizagem. (Professora Orquídea).

Percebemos nas narrativas que as professoras notaram a necessidade de mudança na prática, em compreender os saberes que os alunos trazem e transformam em pergunta trazendo para a sala quando surge a oportunidade para essa expressão ou como curio- sidade ou como dúvida, mas, que as duas condições são elementos importantes para um bom momento de ampliar e ressignificar a aula a partir da reflexão. A reflexão por si só não basta, "é necessário que o professor seja capaz de tomar posições concretas" (PIMENTA, 2006, p.22).

Quando perguntamos se as professoras pretendiam modificar algo no planejamento e organização do trabalho pedagógico, todas as docentes foram unânimes em responder que sim. Demo (2005, p.38) afirma que "aprender é uma das marcas típicas da competência humana do esforço reconstrutivo pessoal e coletivo", o que nos ajudou a perceber que estava em curso uma reconstrução na prática.

O exercício da reflexão foi marcante depois das discussões na oficina, quando as professoras perceberam com algo que foi manifestado na prática deles a partir das situações relatadas na entrevista. Cada ação apresentada foi suscitando diversas discussões refletindo uma nova postura das professoras, repensando seu fazer pedagógico no exercício da função de educar.
Após a vivência da pesquisa mudei muito minha visão com relação aos questionamentos. Depois que parti- cipei do encontro me ajudou bastan- te a rever o meu conceito. Então, pra mim faz necessário mais encon- tro, mais aprofundamento a respeito desse tema. (Professora Rosa).

Nos relatos, ficaram evidentes que as professoras manifestaram uma mudança na concepção no que tange aos saberes do aluno no contexto da aula, compreendendo o questionamen- 
to do aluno como elemento importante para incluir no processo pedagógico, a serem reorganizados como possibilidades de envolvimento na aprendizagem, propiciando um refazer da prática e também a necessidade de continuidade de formação.

Refletir no contexto da prática é reorganizar a prática, dessa forma, Pimenta (2006, p.43) afirma "que o professor pode produzir conhecimento a partir da prática, desde que a investigação reflita intencionalmente sobre ela, problematizando os resultados obtidos com o suporte da teoria". Nesse sentido, faz-se necessário refletir a prática a partir de uma teoria num desafio de inovar os conhecimentos reconstruindo saberes com elementos de organicidade da prática.

$\mathrm{Na}$ concretude da reflexão a respeito desse aspecto, emergiu a seguinte pergunta: Os questionamentos sobre os fenômenos da natureza trazidos pelos alunos são importantes e podem ser inseridos na organização do seu planejamento?

Sim, são de extrema importância, eu sempre insiro nos meus planos, pois acho importante o professor se mostrar interessados aos questionamentos trazidos por eles. (Professora Cravo).

Sim, com certeza, pois é através do conhecimento do educando que aprimoro o meu planejamento, que disse anterior, na pergunta anterior né, eu posso trabalhar em cima daquele questionamento do aluno. (Professora Lírio).

Sim, pode ser articulado e também organizado, você fazer o seu plano e inserir, mas você tem que fazer o seu plano inserido no questionamento dos alunos. Você tem que se adequar ao que o menino traz de lá para cá, porque como eu digo você tem um plano na cabeça, e o aluno vem e você tem que jogar aquele questionamento dos alunos aqui dentro do plano, é simplesmente você só, juntar tudo, não mudar totalmente o plano, mas adequar. (Professora Hortência).

Falando da prática e como será após a pesquisa frente aos questionamentos dos alunos, uma professora respondeu que terá primeiramente uma prática respeitosa, entende-se que respeitará os saberes dos alunos, sua cultura, seu jeito de pensar, dirigindo sua atenção para o papel das vivências prévias das crianças, as suas experiências de vida. Consistindo em momentos de situações significativas, em um ambiente rico e apropriado para uma prática que favoreça uma construção de saberes e formação de novos conceitos precisos e de organização do conhecimento adquirido coletivamente. Em vista disso, a formação de professores é uma prática educativa visando a mudanças qualitativas no desenvolvimento e na aprendizagem (LIBÂNEO, 2002, p.60).

Nas narrativas, percebemos também que, no contexto formativo, a reflexão da prática reside como primordial visando construir novas experiências para atender aos alunos. É nesse ciclo de aprendizagem que sendo professor e aluno no exercício pleno da sua função que aprende, reconstrói saberes de princípios pedagógicos, teóricos e, sobretudo, "aprender a aprender que é competência de construir competência" segundo Demo (2015, p.224), para intervir nas ações que de fato os alunos possam construir auto- 
nomia e que o professor possa resolver problemas e desafios que surgem no cotidiano do espaço escolar.

\section{Considerações finais}

As crianças trazem questionamentos inusitados para os professores, que, por muito tempo, foram vistos como detentores do saber. Essa é uma concepção que fez parte da formação de muitos docentes, inclusive dos que participaram desta pesquisa. Mas hoje as inquietações das crianças podem se constituir em ensejo para a formação continuada em serviço de docentes do ciclo de alfabetização do ensino fundamental?

O presente estudo possibilitou momentos de discussão e reflexão da ação pedagógica e uma dialogicidade com os seus pares, construindo conhecimentos específicos na perspectiva dos questionamentos dos alunos nas aulas, e também, mediante as narrativas após a oficina de formação. A partir daí ficou evidente possibilidades de mudanças importantes na prática pedagógica do grupo de professores participantes da pesquisa.

Defendemos que, no processo de questionamento reconstrutivo citado por Demo (2015), professores e alunos aprendem juntos e é preciso ressignificar a prática pedagógica para promover uma educação para além dos muros escolares. Assim, os encontros formativos fazem parte do processo de construção de conhecimento e construção de uma identidade profissional, pois ali são geradas discussões da prática que levam os professores à reflexão da ação.
Observamos que o professor deixa de ser um mero transmissor de conteúdo e técnicas e assume o papel de articulador, mediador da aprendizagem e a todo o momento será obrigado a tomar decisões diante dos questionamentos inquietantes dos alunos. Nossa análise permitiu constatar que os questionamentos dos alunos são importantes quando coloca o aluno no confronto com os saberes do cotidiano, envolvendo-o nesse processo de busca de integração do conhecimento com o vivido.

Esse estudo torna evidente a forma como os questionamentos transformam o aprendizado dos educandos de maneira significativa e prazerosa, transformando os conhecimentos a partir dos saberes existentes dos alunos, emergindo um sujeito ativo e participativo. A prática perpassa por diversos saberes e que evidenciam no contexto da sala, mas é necessário compreender esse processo de modo geral como um atributo de novos saberes porque precisa ser ressignificada em cada desafio vivenciado e serem reelaborado em constantes processos formativos.

$\mathrm{O}$ questionamento dos alunos pode ser considerado o ponto de partida e de chegada para a organização da prática pedagógica do professor. A expressividade organizativa da prática será possível a partir das relações e interações com outras práticas em que se imbricam, assumindo novas significações.

Este estudo contribuiu para o desenvolvimento da formação continuada no contexto do professor. Embora as políticas de formação tenham 
avançado, as práticas ainda continuam fora do contexto vivido na escola, sem representação curricular no que tange aos questionamentos que os alunos trazem do seu entorno. Portanto, defendemos que são necessárias forma- ções continuada que atendam às necessidades específicas do professor em todos os segmentos, e que o exercício diário de reflexão a partir das vivências no cotidiano escolar sejam uma constante na prática pedagógica. 


\section{Referências}

BRASIL. Ministério de Educação e Cultura. LDB - Lei no 9394/96, de 20 de dezembro de 1996. Estabelece as diretrizes e bases da Educação Nacional. Brasília: MEC, 1996.

DELIZOICOV, D.; ANGOTTI, J. A.P. Metodologia do ensino de ciências. São Paulo: Cortez, 1994. - (Coleção magistério $2^{\circ}$ grau. Série formação do professor).

DEMO, Pedro. Educar pela pesquisa. $10^{\mathrm{a}}$ ed. Campinas, São Paulo: Autores Associados, 2015.

FREIRE, Ana Maria Araújo De. Paulo Freire: Uma História de vida. $1^{\text {a }}$ ed. Editora Villa das Letras. Indaiatuba, SP. 2006.

FREIRE, Paulo. Pedagogia da autonomia: saberes necessários à prática educativa. São Paulo: Paz e Terra, 1996 (Coleção Leitura).

FREIRE, Paulo; FAUNDEZ, Antônio. Por uma Pedagogia da Pergunta. Rio de Janeiro: Paz e Terra, 1995

LIBANÊO, José Carlos. Reflexividade e formação de professores: outra oscilação do pensamento pedagógico. In: PIMENTA, Selma; GHEDIN, Evandro (orgs.). Professor reflexivo no Brasil: gênese e crítica de um conceito. São Paulo: Cortez; 2002.

LÜDKE, M; ANDRÉ, M. E. D. A. Pesquisa em educação: abordagens qualitativas. $2^{a}$ ed. São Paulo: E.P. U, 2014.

MORAES, Roque. Uma tempestade de luz: a compreensão possibilitada pela análise textual discursiva. Ciência \& Educação: Bauru, SP, v. 9, n. 2, p. 191-210, 2003.

MORAES, Roque; GALIAZZI, Maria do Carmo. Análise textual discursiva: processo reconstrutivo de múltiplas faces. Ciência \& Educação, Bauru, v. 12, n. 1, p.117$128,2006$.

MORAES, Roque; RAMOS, M.G.; GALIAZZI, Maria do Carmo. A epistemologia do aprender no educar pela pesquisa em ciências: alguns pressupostos teóricos. In: MORAES, Roque; MANCUSO, R. Educação em Ciências. Ijuí: Unijuí, 2004.

NÓVOA, Antônio. Formação de professores e formação docente. In: NÓVOA, Antônio. Os professores e a sua formação. Publicações Dom Quixote, Lisboa, 1992.

PIMENTA, S. G. Professor Reflexivo no Brasil: gênese e crítica de um conceito. $4^{\text {a }}$ ed. São Paulo: Cortez, 2006. 
SCHÖN, D. Formar Professores como profissionais reflexivos. In: NÓVOA, Antônio (Coord.). Os professores e sua formação. $3^{\text {a }}$ ed. Lisboa: Dom Quixote, 1997.

VEIGA, Ilma Passos Alencastro; D'ÁVILA, Cristina Maria (Org). Profissão docente: novos sentidos, novas perspectivas. $2^{\mathrm{a}}$ ed. Campinas, São Paulo: Papiros, 2012.

O(s) autor(es) se responsabiliza(m) pelo conteúdo e opiniões expressos no presente artigo, além disso declara(m) que a pesquisa é original.

Recebido em 19/03/2020

Aprovado em 21/06/2020 